\title{
A case of hemichorea in RNF213-related vasculopathy
}

\author{
Satoshi Hosoki, Takeshi Yoshimoto and Masafumi Ihara ${ }^{*}$ (D)
}

\begin{abstract}
Background: Internal carotid artery (ICA) stenosis has been recently reported to cause hemichorea, mainly in East Asia. The East Asian-specific p.R4810K variant of RNF213, a susceptibility gene for moyamoya disease (MMD), accounts for up to $25 \%$ of sporadic ischemic stroke with ICA stenosis cases in East Asia. However, as RNF213-related vasculopathy does not meet the diagnostic criteria for MMD, the creation of a new disease category has been suggested. Here, we report the first case of hemichorea in RNF213-related vasculopathy.

Case presentation: An 81-year-old woman was admitted to our hospital with choreic movements in the periphery of the right extremities at rest. Though head magnetic resonance imaging showed no fresh or old cerebral infarction, ${ }^{123}$-iodoamphetamine-single photon emission computed tomography showed cerebral blood flow of < $80 \%$ in the anterior territory of the left middle cerebral artery (MCA) in a resting state and cerebrovascular reactivity of $<10 \%$ in the broader area supplied by the left MCA after acetazolamide challenge. Head magnetic resonance angiography and digital subtraction angiography revealed left ICA C1 portion stenosis with compromised collateral vessels. Involuntary movements resolved with haloperidol administration within 3 days, without apparent recurrence from continuation of the medication for a year. Genetic testing revealed the presence of the heterozygous RNF213 p.R4810K variant.

Conclusions: Chorea is thought to be caused by damage to circuitry connecting the basal ganglia with the cerebral cortex, as found in cases of MMD, which possess aberrant vessels in the basal ganglia. However, aberrant vessels and cerebral infarctions were not observed in the basal ganglia in the current case, decreasing the likelihood of a role in chorea. Alternatively, as RNF213 regulates vascular endothelial function and angiogenesis, dysregulation may impair the neurovascular unit and damage basal ganglia circuitry, contributing to the development of chorea. This case may renew interest in the concept of RNF213-related vasculopathy and the pathophysiological mechanisms behind chorea in ICA stenosis.
\end{abstract}

Keywords: Carotid stenosis, Chorea, RNF213, Moyamoya disease, East-west gradient

\section{Background}

Chorea is characterized by abrupt involuntary movements resulting from a continuous flow of random muscle contractions [1]. Internal carotid artery (ICA) stenosis rarely causes chorea but has been recently reported to cause hemichorea. These reports emanate mainly from East Asia [2-11] (Table 1), though the

\footnotetext{
* Correspondence: ihara@ncvc.go.jp

Department of Neurology, National Cerebral and Cardiovascular Center, 6-1 Kishibe-Shimmachi, Suita, Osaka 564-8565, Japan
}

reason for the regional difference is not clear. Nonetheless, chorea is found relatively frequently in $3.3-4.2 \%$ of patients with ICA stenosis caused by rare moyamoya disease (MMD) [12]. MMD shows a characteristic 'EastWest gradient' geographical pattern of the disease prevalence because of the East Asian-specific RNF213 p.R4810K variant [13]. Furthermore, this nonsynonymous p.R4810K variant accounts for up to $25 \%$ of sporadic ischemic stroke with ICA stenosis in East Asia, even without meeting the diagnostic criteria of MMD [14],

(c) The Author(s). 2021 Open Access This article is licensed under a Creative Commons Attribution 4.0 International License, which permits use, sharing, adaptation, distribution and reproduction in any medium or format, as long as you give appropriate credit to the original author(s) and the source, provide a link to the Creative Commons licence, and indicate if changes were made. The images or other third party material in this article are included in the article's Creative Commons licence, unless indicated otherwise in a credit line to the material. If material is not included in the article's Creative Commons licence and your intended use is not permitted by statutory regulation or exceeds the permitted use, you will need to obtain permission directly from the copyright holder. To view a copy of this licence, visit http://creativecommons.org/licenses/by/4.0/ The Creative Commons Public Domain Dedication waiver (http://creativecommons.org/publicdomain/zero/1.0/) applies to the data made available in this article, unless otherwise stated in a credit line to the data. 
Table 1 Cases of hemichorea caused by internal carotid artery stenosis, which did not meet the diagnostic criteria of moyamoya disease

\begin{tabular}{|c|c|c|c|c|c|}
\hline Age & Sex & $\begin{array}{l}\text { Side of } \\
\text { chorea }\end{array}$ & Basal ganglia infarction (if not, location of infarction) & Country & Reference \\
\hline 77 & Female & Rt. & Bil. basal ganglia, rt. caudate nucleus and bil. centrum semiovale & Japan & {$[2]$} \\
\hline 60 & Male & Lt. & No basal ganglia infarction (Rt. centrum semiovale) & England & [3] \\
\hline 75 & Male & Rt. & No basal ganglia infarction (Lt. posterior parietal gray matter) & England & [4] \\
\hline 73 & Male & Rt. & No basal ganglia infarction (Lt. anterior parietal lobe) & England & [4] \\
\hline 75 & Male & Lt. & $\begin{array}{l}\text { No basal ganglia infarction (Rt. fronto-parietal subcortical white matter and centrum } \\
\text { semiovale) }\end{array}$ & Japan & [5] \\
\hline 75 & Male & Lt. & No basal ganglia infarction (Bil. corona radiata) & Japan & [2] \\
\hline 67 & Female & Lt. & No basal ganglia infarction (Rt. anterior border zone) & Korea & [6] \\
\hline 72 & Female & Rt. & No infarction & England & [4] \\
\hline 81 & Male & Rt. & No infarction & Spain & [7] \\
\hline 72 & Male & Bil. & No infarction & Japan & [8] \\
\hline 73 & Male & Lt. & No infarction & Japan & [9] \\
\hline 73 & Male & Lt. & No infarction & Japan & [10] \\
\hline 71 & Male & Lt. & No infarction & Japan & [11] \\
\hline 81 & Female & Lt. & No infarction & Japan & This case \\
\hline
\end{tabular}

Abbreviations: bil Bilateral, $r$ Right, It Left

which has led to a novel disease concept of RNF213-related vasculopathy [13]. Here, we report the first case of hemichorea in a RNF213-related vasculopathy other than MMD, which may help define the clinical spectrum of RNF213-related vasculopathy.

\section{Case presentation}

An 81-year-old woman noticed choreic movements in the periphery of the right lower extremity at rest, which gradually became more frequent. One month later, she also noticed involuntary movements in the periphery of the right upper extremity and was admitted to our hospital. On admission, she displayed involuntary, irregular, and nonrhythmic movements in the periphery of the right extremities without other neurological deficits. She had a medical history of hypertension and dyslipidemia but no family history of cerebrovascular disorders or chorea. Blood and cerebrospinal fluid tests and cervical and lumbar spine magnetic resonance imaging (MRI) were normal. Head MRI showed no fresh or old cerebral infarction (Fig. 1a). However, ${ }^{123}$ I-iodoamphetamine-single photon emission computed tomography showed cerebral blood flow $<80 \%$ in the anterior territory of left middle cerebral artery (MCA) in a resting state (Fig. 1b) and cerebrovascular reactivity $<10 \%$ in the broader area supplied by the left MCA after acetazolamide challenge (Fig. 1c). Head magnetic resonance angiography (MRA) and digital subtraction angiography revealed left ICA C1 portion stenosis with poor collateral vessels (Fig. 1d, e). She refused recommended extracranial-intracranial bypass surgery; however, the involuntary movements resolved with haloperidol administration within 3 days, without apparent recurrence from continuation of the medication for a year. Follow-up head MRI and MRA taken 1 year later showed no interval changes (Fig. 2a, b). Genetic testing performed with Taqman probes (TaqMan SNP Genotyping Assays; Applied Biosystems) using a 7300/7500 Real-Time PCR System (Applied Biosystems) [15] revealed the presence of the heterozygous RNF213 p.R4810K variant.

\section{Discussion and conclusions}

We detail a case of unilateral intracranial ICA stenosis presenting with hemichorea. This case did not meet the diagnostic criteria of MMD [14] because of the presence of unilateral intracranial stenosis of ICA without aberrant vessels in the basal ganglia; however, the patient was found to carry the RNF213 p.R4810K variant, which has been strongly associated with MMD [16]. We and others have reported this variant as a key factor in ischemic stroke with intracranial arterial stenosis, a common stroke subtype found in East Asian cases, and termed 'RNF213-related vasculopathy' $[13,16]$. This report may indicate a possible explanation of why ICA stenosis leads to chorea more predominantly in East Asia and potentially widens the disease spectrum of RNF213-related vasculopathies through inclusion of chorea as an additional clinical symptom. As with MMD, previous reports have suggested a predominance of hemichorea in ICA stenosis in East Asian cases, which we have termed 

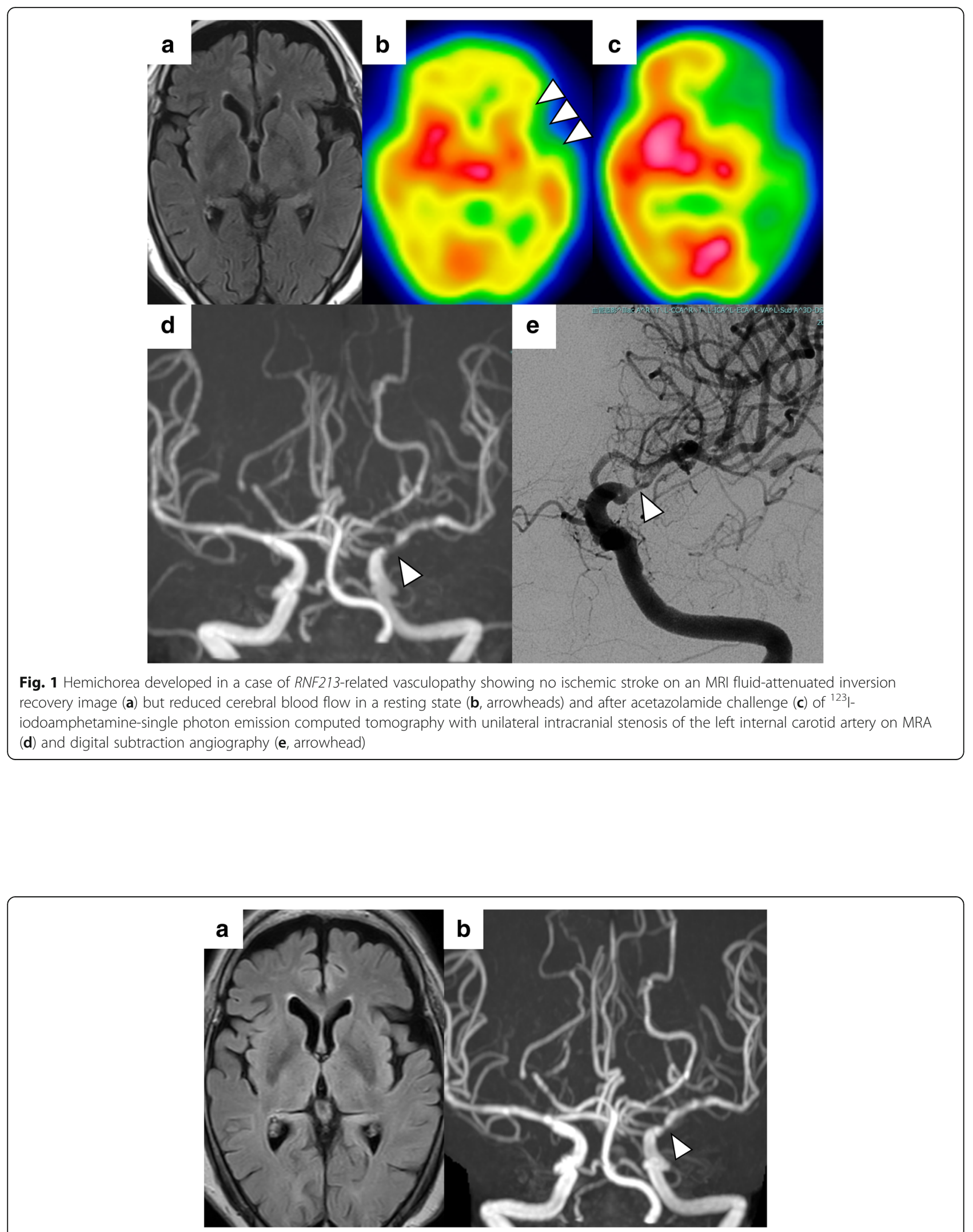

Fig. 2 Follow-up head MRI fluid-attenuated inversion recovery image (a) and MRA (b) taken one year later showed no interval changes, including unilateral intracranial stenosis of the left internal carotid artery (b, arrowhead) 
the 'East-West gradient' [11], possibly indicating the importance of not only hemodynamic change, but also the ethnicity-specific RNF213 p.R4810K variant, in hemichorea development. Chorea is thought to be caused by damage to circuitry connecting the basal ganglia with the cerebral cortex [1], as found in cases of MMD with aberrant vessels in the basal ganglia [12]. However, aberrant vessels were not observed in the basal ganglia in the current case, decreasing likelihood of a role in chorea. Alternatively, as RNF213 encodes a protein containing two ATPases associated with diverse cellular activities and an E3 ligase domain that regulate vascular endothelial function and angiogenesis [17], dysfunctional RNF213 may directly damage neural circuitry, contributing to development of chorea. Indeed, we recently reported endothelial cell specific RNF213 mutant (human p.R4810K orthologue) transgenic mice had delayed recovery of cerebral blood flow, more profoundly in the basal ganglia than the cerebral cortex, after cerebral hypoperfusion induced by carotid artery stenosis [18]. Therefore, endothelial damage and resultant neural dysfunction in the basal ganglia may be associated with chorea. Additional cases will be required to uncover the mechanism of the genotype-phonotype association, which may be being obscured by the low penetrance of RNF213 variant and susceptibility to environmental factors $[15,19,20]$.

In conclusion, this case may expand and renew the disease concept of RNF213-related vasculopathy and elaborate on the pathophysiological mechanisms behind chorea in ICA stenosis.

\section{Abbreviations}

ICA: Internal carotid artery; MMD: Moyamoya disease; MCA: Middle cerebral artery; MRI: Magnetic resonance imaging; MRA: Magnetic resonance angiography

\section{Acknowledgments}

We are indebted to Dr. Ahmad Khundakar for his editorial assistance and helpful comments.

\section{Authors' contributions}

$\mathrm{SH}$ was the first author, collected patient data and wrote the manuscript. $\mathrm{Ml}$ was a major contributor in writing the manuscript. TY contributed to revision of the manuscript and genetic testing. All authors have read and approved the final manuscript.

\section{Funding}

Not applicable.

\section{Availability of data and materials}

Not applicable.

\section{Ethics approval and consent to participate}

Not applicable.

\section{Consent for publication}

We have obtained written informed consent for this publication from the patient.

\section{Competing interests}

The authors declare they have no competing interests.

Received: 8 October 2020 Accepted: 17 January 2021

Published online: 22 January 2021

\section{References}

1. Cardoso F, Seppi K, Mair KJ, Wenning GK, Poewe W. Seminar on choreas. Lancet Neurol. 2006;5(7):589-602. https://doi.org/10.1016/s14744422(06)70494-x.

2. Morigaki R, Uno M, Suzue A, Nagahiro S. Hemichorea due to hemodynamic ischemia associated with extracranial carotid artery stenosis. Report of two cases. J Neurosurg. 2006;105(1):142-7. https://doi.org/10.3171/jns.2006.105.1. 142.

3. Waterston JA, Brown MM, Butler P, Swash M. Small deep cerebral infarcts associated with occlusive internal carotid artery disease. A hemodynamic phenomenon? Arch Neurol. 1990;47(9):953-7. https://doi.org/10.1001/ archneur.1990.00530090023007.

4. Galea I, Norwood F, Phillips MJ, Shearman C, McMonagle P, Gibb WR. Pearls \& Oy-sters: resolution of hemichorea following endarterectomy for severe carotid stenosis. Neurology. 2008;71(24):e80-2. https://doi.org/10.1212/01. wnl.0000336975.80810.74.

5. Fukui T, Hasegawa Y, Seriyama S, Takeuchi T, Sugita K, Tsukagoshi H. Hemiballism-hemichorea induced by subcortical ischemia. Can J Neurol Sci. 1993;20(4):324-8.

6. Kim DW, Ko Y, Jang SH, Yoon SJ, Oh GS, Lee SJ, et al. Acute hemichorea as an unusual presentation of internal carotid artery stenosis. J Mov Disord. 2013;6(1):17-20. https://doi.org/10.14802/jmd.13004.

7. Pareés I, Pujadas F, Hernández-Vara J, Lorenzo-Bosquet C, Cuberas G, Munuera J, et al. Reversible hemichorea associated with extracranial carotid artery stenosis. J Neurol Sci. 2011;300(1-2):185-6. https://doi.org/10.1016/j. jns.2010.08.068.

8. Shimizu T, Hiroki M, Yamaoka Y, Kato S, Suda M, Ide K, et al. Alternating paroxysmal hemiballism-hemichorea in bilateral internal carotid artery stenosis. Intern Med. 2001:40(8):808-12. https://doi.org/10.2169/ internalmedicine.40.808

9. Kodera Y, Nakayama T, Yutani S, Uesugi T, Ohnuki Y, Takizawa S. Hemichorea improved by carotid artery stenting in a 73-year-old man with hypoperfusion of the basal ganglia. Rinsho Shinkeigaku. 2015;55(5):356-9. https://doi.org/10.5692/clinicalneurol.cn-000641.

10. Noda K, Ishimoto R, Hattori N, Okuma Y, Yamamoto T. Hemichorea improvement following endarterectomy for internal carotid artery stenosis. J Neurol Sci. 2016;371:45-7. https://doi.org/10.1016/j.jns.2016.10. 019.

11. Muguruma K, Motoda A, Sugimoto T, Kitamura T. A case of hemichorea caused by right internal carotid artery stenosis. Rinsho Shinkeigaku. 2019; 59(8):509-14. https://doi.org/10.5692/clinicalneurol.cn-001276.

12. Ahn ES, Scott RM, Robertson RL Jr, Smith ER. Chorea in the clinical presentation of moyamoya disease: results of surgical revascularization and a proposed clinicopathological correlation. J Neurosurg Pediatr. 2013;11(3): 313-9. https://doi.org/10.3171/2012.11.PEDS12199.

13. Okazaki S, Morimoto T, Kamatani Y, Kamimura T, Kobayashi H, Harada K et al. Moyamoya disease susceptibility variant RNF213 p.R4810K increases the risk of ischemic stroke attributable to large-artery atherosclerosis. Circulation. 2019;139(2):295-8. https://doi.org/10.1161/CIRCULATIONAHA. 118.038439 .

14. Guidelines for diagnosis and treatment of moyamoya disease (spontaneous occlusion of the circle of Willis). Neurol Med Chir (Tokyo). 2012;52(5):245-66. https://doi.org/10.2176/nmc.52.245

15. Liu W, Morito D, Takashima S, Mineharu Y, Kobayashi H, Hitomi T, et al. Identification of RNF213 as a susceptibility gene for moyamoya disease and its possible role in vascular development. PLoS One. 2011;6(7):e22542. https://doi.org/10.1371/journal.pone.0022542.

16. Bang OY, Chung JW, Kim DH, Won HH, Yeon JY, Ki CS, et al. Moyamoya disease and spectrums of RNF213 vasculopathy. Transl Stroke Res. 2020; 11(4):580-9. https://doi.org/10.1007/s12975-019-00743-6.

17. Kamimura T, Okazaki S, Morimoto T, Kobayashi H, Harada K Tomita T, et al. Prevalence of RNF213 p.R4810K variant in early-onset stroke with intracranial arterial stenosis. Stroke. 2019;50(6):1561-3. https://doi.org/10.1161/strokeaha. 118.024712 . 
18. Morimoto T, Enmi Jl, Hattori Y, Iguchi S, Saito S, Harada KH, et al. Dysregulation of RNF213 promotes cerebral hypoperfusion. Sci Rep. 2018;8(1):3607. https://doi.org/10.1038/s41598-018-22064-8.

19. Liu W, Hitomi T, Kobayashi H, Harada KH, Koizumi A. Distribution of moyamoya disease susceptibility polymorphism p.R4810K in RNF213 in east and southeast Asian populations. Neurol Med Chir (Tokyo). 2012;52(5):299303. https://doi.org/10.2176/nmc.52.299.

20. Koizumi A, Kobayashi H, Hitomi T, Harada KH, Habu T, Youssefian S. A new horizon of moyamoya disease and associated health risks explored through RNF213. Environ Health Prev Med. 2016;21(2):55-70. https://doi.org/10.1007/ s12199-015-0498-7.

\section{Publisher's Note}

Springer Nature remains neutral with regard to jurisdictional claims in published maps and institutional affiliations.

Ready to submit your research? Choose BMC and benefit from:

- fast, convenient online submission

- thorough peer review by experienced researchers in your field

- rapid publication on acceptance

- support for research data, including large and complex data types

- gold Open Access which fosters wider collaboration and increased citations

- maximum visibility for your research: over $100 \mathrm{M}$ website views per year

At $\mathrm{BMC}$, research is always in progress.

Learn more biomedcentral.com/submissions 